\title{
Assessment of sedation level for endoscopic retrograde cholangiopancreatography - a prospective validation study
}

\author{
Jokelainen, Jarno
}

2018

Jokelainen , J , Mustonen , H , Kylänpää , L , Udd , M , Lindström , O \& Pöyhiä , R 2018 , ' Assessment of sedation level for endoscopic retrograde cholangiopancreatography - a prospective validation study ' , Scandinavian Journal of Gastroenterology , vol. 53 , no. 3 , pp. 370-375 . https://doi.org/10.1080/00365521.2018.1435715

http://hdl.handle.net/10138/311385

https://doi.org/10.1080/00365521.2018.1435715

acceptedVersion

Downloaded from Helda, University of Helsinki institutional repository.

This is an electronic reprint of the original article.

This reprint may differ from the original in pagination and typographic detail.

Please cite the original version. 
Assessment of sedation level for endoscopic retrograde cholangiopancreatography a prospective validation study

Jarno Jokelainen a,b, Harri Mustonen c, Leena Kylänpää c, Marianne Udd c, Outi Lindström c and Reino Poyhiä b,d

a Department of Anesthesia and Intensive Care Medicine, South Karelia Central Hospital, Lappeenranta, Finland;

b Faculty of Medicine, University of Helsinki, Helsinki, Finland;

c Department of Gastroenterological and General Surgery, Helsinki University Hospital, University of Helsinki, Helsinki, Finland;

d Kauniala Hospital, Kauniainen, Finland 


\title{
Assessment of sedation level for endoscopic retrograde
}

\section{cholangiopancreatography - a prospective validation study}

\begin{abstract}
Background and aims: There is no consensus on how to assess the depth of sedation for Endoscopic Retrograde Cholangiopancreatography (ERCP). This study was carried out in order to evaluate different methods of assessment of depth of sedation: Bispectral Index (BiS), modified Richmond Agitation/Sedation Scale (mRASS), modified Ramsay Sedation Scale, (mRSS) and modified Observer Assessment of Alertness and Sedation (mOAAS) and their applicability to clinical practice.
\end{abstract}

Methods: 200 patients were recruited. Sedation was given by standard clinical practice using propofol sedation or patient controlled sedation. Sedation was assessed on all patients using the above-mentioned methods. BiS was considered the reference point for sedation scales. Cronbach's alpha was calculated to determine the consistency of different scales in respect to each other and prediction probability and Spearman correlation coefficients of sedation scales were calculated to show the relationship between sedation scales and BiS.

Results: All scales showed high reliability with overall Cronbach's alpha was 0.943. Dropping scales suggested better consistency between mOAAS, mRSS and mRASS than with BiS. Spearman correlation and prediction probability showed similar results with all tested scales: mOAAS $(0.695$, 0.739), mRSS $(0.673,0.735), \operatorname{mRASS}(0.683,0.738), \mathrm{P}<.01$ for all scales 
Conclusions: All tested methods were found to be reliable in the assessment of the depth of sedation when compared with each other. However, mRASS, mRSS, mOAAS require the patient to respond to verbal or tactile stimulus, which may impair execution of ERCP, whereas BiS information is collected directly from electroencephalogram and thus may be preferable in clinical setting.

\section{Keywords}

Sedation, Endoscopic Retrograde Cholangiopancreatography, Bispectral index, Sedation scale 


\section{Introduction and Background}

Endoscopic retrograde cholangiopancreatography $(\mathrm{ERCP})$ is a technically challenging endoscopic procedure that usually requires moderate to deep sedation in order to be successful due to substantial procedural discomfort and pain (1-3). Currently there is no consensus on how the level of sedation should be measured during ERCP.

Bispectral index (BiS) monitoring is an electroencephalogram (EEG) based-method which analyzes the EEG signal with an algorithm that produces a simple index score that was developed to assess the depth of general anesthesia, but has also been used to monitor the depth of sedation. BiS has been used in studies on ERCP sedation with some success (4-7). Other methods of assessing the depth of sedation for ERCP have also been used in studies, such as the Richmond Agitation/Sedation Scale (RASS)(8), a modified Ramsay Sedation Scale (mRSS)(9) and modified Observer Assessment of Alertness and Sedation (mOAAS) $(4,6)$. These are all assessed by clinical evaluation and by verbal, tactile or painful stimuli. Also, these scales are designed to be used in intensive care units and may not be ideal for use during procedural sedation. This study was performed in order to evaluate the usefulness and practicality of the aforementioned methods of assessing the depth of sedation during ERCP. 


\section{Methods}

This study was approved by the institutional Ethics Committee of Helsinki University Central Hospital (Ethics Committee, Department of Surgery, Biomedicum Helsinki 2 C, Tukholmankatu 8 C, PL 705, 00029 HUS, Finland. DNRO 336/13/03/02/2012) on December $12^{\text {th }}, 2012$. The study was registered on clinicaltrials.gov, identifier NCT01747733.

All adult patients coming to an ERCP procedure were eligible for this study. 200 patients were recruited for this study after written consent. Exclusion criteria were refusal to participate and incapability of giving informed consent.

This study was conducted in the endoscopic unit of Meilahti Hospital, a tertiary university clinic, where over 1200 ERCP procedures are performed annually. The first patient entered the study December $11^{\text {th }}, 2013$ and the last patient January $19^{\text {th }}, 2016$.

Sedation was given by standard clinical practice using one of three methods. Patient controlled sedation (PCS), which was administered via a syringe-driver with a self-administration unit (Syramed $\mu$ SP6000; Arcomed AG, Regensdorf, Switzerland) was first. The syringe was prepared with propofol and alfentanil to achieve the following concentrations: propofol $8 \mathrm{mg} / \mathrm{ml}$ and alfentanil $0.06 \mathrm{mg} / \mathrm{ml}$. A patient could take a $1 \mathrm{ml}$ dose of this solution when needed, no lock-out time or dose-limit was programmed. A second technique was the same PCS device operated by the anesthesiologist. The third option was anesthesiologist administered sedation (AAS) with propofol administered as infusion and boluses when needed. Additional doses of opioids, alfentanil or fentanyl were used when deemed necessary by the anesthesiologist. Patients using PCS were allowed to have an initial dose of fentanyl $0,25-0,5 \mu \mathrm{g}$ i.v. in the beginning of the procedure. If the patient was not able to use PCS successfully, the anesthesiologist continued administering sedation either via PCS device or propofol sedation according to clinical judgment (PCS+AAS). 
The following data of each patient was registered in a prospective manner: age, weight, height, American Society of Anesthesiology physical status classification (ASA), duration of the procedure, sedation details (PCS, PCS solution administered by the anesthesiologist, propofol sedation, consumption of sedative medication). Heart rate, rate of breathing, end tidal $\mathrm{CO}_{2}$ and peripheral oxygen saturation $\left(\mathrm{SpO}_{2}\right)$ and non-invasive blood pressure (NIBP) was recorded before, at 5 min intervals during and at the end of the procedure. Hypotension was defined as systolic blood pressure $<90 \mathrm{mmHg}$ and hypoxemia was defined as $\mathrm{SpO}_{2}<90 \%$. The level of sedation was assessed using RASS, mRSS, mOAAS and Bis before, at 5-minute intervals during and at the end of the procedure. Use of other medications and possible adverse effects due to sedation were recorded. The different sedation scales used are shown in Table 1.The satisfaction of the endoscopist to the sedation (ease of inserting the endoscope, patient co-operation (low number when lightly sedated (optimally), high when deeply sedated by definition), gagging, coughing, belching, distracting movement by the patient using a 4 step scale from none to plenty and difficulty of the procedure by The Schutz scale(10)) and patient satisfaction (a seven step scale from highly dissatisfied to highly satisfied) were recorded. BiS was considered the reference point for sedation scales because it is an objective figure whereas the other scales are subjective assessments of sedation level.

The results are reported as medians and interquartile ranges (median [IQR]) or number of patients and percentages. The prediction probability $\mathrm{P}_{\mathrm{K}}(11)$ and a Spearman correlation coefficient were calculated to show the relationship between the different sedation scales and BiS. For calculation of $\mathrm{P}_{\mathrm{K}}, \mathrm{BiS}$ was categorized, $<50$ in one group, and $>50$ values at 10 score steps up to 100 (five groups). Cronbach's alpha was calculated to determine the consistency of different sedation scales in respect to each other. Multilevel ROC-curves were used to illustrate the specificity and sensitivity of different sedation scales in relation to BiS. BiS was divided into 3 categories: light sedation 
$\mathrm{BiS}>85$, moderate sedation Bis $65-85$, deep sedation $\mathrm{BiS}<65$. Correlation between sedation sacles and endoscopist or patient satisfaction was calculated using Spearman's rho. Since the order of scales are different, the Ramsay score was analyzed in reverse order to have scales in the same order i.e. lower end values mean deep sedation. Statistical calculations were generated using IBM SPSS Statistics 24 (International Business Machines Corporation, Endicott, NY, USA), Medcalc Statistical software v 17.6 (Ostend, Belgium) and R v 3.3.2 (12) with pROC package(13). 


\section{Results}

Of the 200 patients 134 received propofol sedation, with one patient receiving only boluses, the remaining patients were sedated with a propofol infusion and boluses. Three patients in the propofol sedation group were also given small doses of ketamine (5-25mg I.v.). PCS was attempted 48 times. PCS was successful 39 times and the anesthesiologist had to intervene 9 times. Overall success rate of PCS was $81,3 \%$. Demographics and drug consumption of the patients as well as endoscopist and patient satisfaction are shown in table 2 .

There were no sedation related adverse effects with patients using PCS successfully. One patient had a short bout of hypoxemia which was corrected by verbal command for the patient to breathe in the PCS+AAS group. In the propofol sedation group there was one case of hypoxemia which was corrected by a nasopharyngeal tube. In the propofol sedation group there was also 15 cases of hypotension, three of which required intervention and received vasopressors (ephedrine, phenylephrine) and one patient with concomitant bradycardia who received glycopyrronium in addition to phenylephrine.

The Cronbach's alpha was calculated among different sedation scales to measure internal consistency. The overall Cronbach's alpha was 0.943, suggesting excellent consistency between the scales. Dropping sedation scales one by one suggested that mOAAS, mRSS and RASS might give more consistent results in between them than with Bis, Table 3.

Prediction probability $\mathrm{P}_{\mathrm{K}}$ and Spearman correlation coefficient of the sedation scales compared to BiS are shown in Table 4. Both prediction probabilities and Spearman correlation coefficients are relatively similar in different sedation scales. PK is the probability that the sedation scale can correctly predict the order of arbitrary pair of distinct observed sedation depths. 
Multilevel ROC-curves for mRSS, mOAAS and RASS are shown in figures 1-3 respectively. Combined multi AUC values and normal AUC values for pairwise comparisons of sedation depths for evaluation performance of mRSS, mOAAS and RASS scales predicting sedation levels are shown in Table 5. Deep sedation was best separated from light sedation by any scale studied. The values in between sedation scales are relatively similar.

There was a weak, but statistically significant correlation between sedation scales used and both endoscopist and patient satisfaction. Correlations are shown in Table 6. 


\section{Discussion}

Monitoring of sedated patients is increased in importance as the level of sedation is deepened. There are several guidelines regarding monitoring of patients undergoing endoscopic procedures $(14,15)$. there is also considerable variability in clinical practice of monitoring sedated patients undergoing endoscopic procedures(16). However, there is not a clear consensus nor guidelines on how the level of sedation should be monitored, even though it is mentioned that the level of consciousness and discomfort should be monitored in some fashion.

In a recent review article(17) it was noted that depth of anesthesia monitoring devices were impacting titration of sedation and could be useful in reducing the amount of sedatives given to patients at least when said devices were used by clinicians familiar with such technology. It was not within the scope of the study to influence the sedation given to patients, the focus of it being the comparison of different methods of evaluating the level of sedation. However, the results of our study may enable this positive effect on patient care as accurate evaluation of the depth of sedation is of great clinical importance in optimizing patient comfort, limiting over sedation and enabling expedient patient flow in the endoscopy theater.

The sedation scales employed in this study are all widely used, both clinically and in clinical studies. In a relatively recent systematic review article by Robinson et al (18) the reliability and validity of sedation scales in clinical use in ICU setting was evaluated using predetermined psychometric assessment of current scientific research. Each of the sedation scales used our research was evaluated in the review article and all were found to be clinically relevant, RASS was evaluated as having very good published psychometric results, RSS rated moderate and mOAAS 
rated as very low published resuls. All sedation scales we studied were found to be reliable in the assessment of the depth of sedation for ERCP when compared with each other. This is not that surprising, considering the fact that the criteria used to assess them are very similar. There is however one problem using these scales during a procedure like ERCP. Determining the depth of sedation requires the patient to respond to a verbal command or tactile stimulus. This may impair the smooth execution of the procedure, since the patient may be adequately sedated before asking to respond, but then experiences arousal and doesn't conform to the procedure as well as before without additional sedatives. This may guide the clinician towards the use of BiS and other such devices such as Entropy ${ }^{\mathrm{TM}}(19)$ and Narcotrend ${ }^{\mathrm{TM}}$ (20), which use EEG and eliminate the need to rouse the patient. Patient and endoscopist satisfaction was generally very high regardless of the method of sedation used. There was a weak correlation with satisfaction and sedation scales. This is to be expected, since deeper sedation will enable better working environment for the endoscopist and cause analgesia and amnesia for the patient and thus alleviate discomfort during the procedure.

A problem of sedating patients for ERCP is the exceedingly varied need for sedation between patients. Some patients, although admittedly very few, need practically no sedation in order to endure the procedure while others require such a deep sedation that it is all but general anesthesia. Having a reliable method of evaluating the depth of sedation that doesn't interfere with the procedure is important to gauge the administration of sedatives in order not to over sedate patients and thus impede the patient flow in the endoscopy unit. While the sedation scales used in this study were all congruent with each other, and showed a good correlation with BiS, their clinical usefulness may be limited in procedural sedation due to the invasive nature of their determination.

There are some limitations to this study. Being a single center study, the applicability of this study to other clinics with different methods of sedation and clinical practice may be limited. However, the scales used have been widely used in different ICU settings and in the case of BiS operating 
theaters worldwide. Therefore, the methods and findings should be generally applicable. Also, the desired level or method of sedation was not determined beforehand but was decided by the anesthesiologist on a case to case basis by clinical experience. Because of this, we cannot give a threshold level of sedation to aim for when sedating patients for ERCP, which also was beyond the scope of this study. Monitoring patients sedated for endoscopy cannot be limited just for sedation. When addressing monitoring, hemodynamic and respiratory parameters need even closer attention than depth of sedation. There are several new methods available, such as transcutaneous $\mathrm{CO}_{2}-$ monitoring(21) and The Integrated Pulmonary Index ${ }^{\circledR}$ (IPI), a mathematically-determined factor based on parameters of capnography and pulse oximetry, which may be used in the detection of impaired respiratory function(22). While the other issues of monitoring are important and worthwhile, we were not looking for a holistic method of monitoring ERCP patients, but focused on depth of sedation, a field we feel is somewhat neglected in this setting in current research.

In conclusion, mOAAS, mRSS and RASS were all found to be highly congruent with each other and slightly less so with BiS, but in clinical practice EEG-derived monitors are more useful in the clinical setting of ERCP sedation. 


\section{Funding details}

No additional funding was received for this study 


\section{Disclosure statement}

The authors report no conflicts of interest. 


\section{References}

1. Garewal D, Powell S, Milan SJ, Nordmeyer J, Waikar P. Sedative techniques for endoscopic retrograde cholangiopancreatography. Cochrane Database of Systematic Reviews.

2012;6(CD007274).

2. Jeurnink SM, Steyerberg E, Kuipers E, Siersema P. The burden of endoscopic retrograde cholangiopancreatography (ERCP) performed with the patient under conscious sedation. Surg Endosc. 2012 Aug;26(8):2213-9.

3. Kapoor H. Anaesthesia for endoscopic retrograde cholangiopancreatography. Acta Anaesthesiol Scand. 2011;55(8):918-26.

4. Jang SY, Park HG, Jung MK, Cho CM, Park SY, Jeon SW, et al. Bispectral index monitoring as an adjunct to nurse-administered combined sedation during endoscopic retrograde cholangiopancreatography. World Journal of Gastroenterology: WJG. 2012 09/22;18(43):6284-9.

5. Paspatis GA, Chainaki I, Manolaraki MM, Vardas E, Theodoropoulou A, Tribonias G, et al. Efficacy of bispectral index monitoring as an adjunct to propofol deep sedation for ERCP: a randomized controlled trial. Endoscopy. 2009;41(12):1046-51.

6. Ramkiran S, Iyer SS, Dharmavaram S, Mohan CVR, Balekudru A, Kunnavil R. BIS Targeted Propofol Sparing Effects of Dexmedetomidine Versus Ketamine in Outpatient ERCP: A Prospective Randomised Controlled Trial. Journal of Clinical and Diagnostic Research : JCDR. 2015 04/02;9(5):UC07-12.

7. von Delius S, Salletmaier H, Meining A, Wagenpfeil S, Saur D, Bajbouj M, et al. Bispectral index monitoring of midazolam and propofol sedation during endoscopic retrograde cholangiopancreatography: a randomized clinical trial (the EndoBIS study). Endoscopy. 2012;44(03):258-64.

8. Jokelainen J, Udd M, Kylänpää L, Mustonen H, Halttunen J, Lindström O, et al. How patientcontrolled sedation is adopted in clinical practice of sedation for endoscopic retrograde cholangiopancreatography? A prospective study of 1196 cases. Scand J Gastroenterol. 2016 10/05:1-7.

9. Ulusoy H, Coskun I, Arslan M. Effects of midazolam or tramadol premedication on early cognitive function in endoscopic retrograde cholangiopancreatography (ERCP): A randomized, controlled, double-blind study. J Int Med Res. 2016 06/01;44(3):542-56.

10. Schutz SM. Grading the degree of difficulty of ERCP procedures. Gastroenterol Hepatol (N Y). 2011 Oct;7(10):674-6.

11. Smith WD, Dutton RC, Smith NT. Measuring the performance of anesthetic depth indicators. Anesthesiology. 1996 Jan;84(1):38-51.

12. R Core Team. R: A Language and Environment for Statistical Computing. R Foundation for Statistical Computing. 2014.

13. Robin X, Turck N, Hainard A, Tiberti N, Lisacek F, Sanchez J, et al. pROC: an open-source package for $\mathrm{R}$ and $\mathrm{S}+$ to analyze and compare ROC curves. BMC Bioinformatics. 2011 Mar $17 ; 12: 77$.

14. ASGE Ensuring Safety in the Gastrointestinal Endoscopy Unit Task Force, Calderwood AH, Chapman FJ, Cohen J, Cohen LB, Collins J, et al. Guidelines for safety in the gastrointestinal endoscopy unit. Gastrointest Endosc. 2014 Mar;79(3):363-72. 
15. Waring JP, Baron TH, Hirota WK, Goldstein JL, Jacobson BC, Leighton JA, et al. Guidelines for conscious sedation and monitoring during gastrointestinal endoscopy. Gastrointest Endosc. 2003 Sep;58(3):317-22.

16. Vaessen HHB, Knape JTA. Considerable Variability of Procedural Sedation and Analgesia Practices for Gastrointestinal Endoscopic Procedures in Europe. Clin endosc. 2016 Jan;49(1):47-55.

17. Conway A, Sutherland J. Depth of anaesthesia monitoring during procedural sedation and analgesia: A systematic review and meta-analysis. Int J Nurs Stud 2017/06;63:201-12.

18. Robinson B, Berube M, Barr J, Riker R, Gelinas C. Psychometric analysis of subjective sedation scales in critically ill adults. Crit.Care Med., 2013, 41, 9 Suppl 1, S16-29.

19. Kwon M, Lee S, Kim T, Kim DK, Lee K, Woo N, et al. Spectral entropy for assessing the depth of propofol sedation. Korean Journal of Anesthesiology. 2011 07/15;62(3):234-9.

20. Amornyotin S, Chalayonnawin W, Kongphlay S. Deep sedation for endoscopic retrograde cholangiopancreatography: a comparison between clinical assessment and Narcotrend(TM) monitoring. Medical Devices (Auckland, N.Z.). 2011 03/17;4:43-9.

21. Miyoshi H, Shimatani M, Kato K, Sumimoto K, Kurishima A, Kusuda T, et al. Transcutaneous monitoring of partial pressure of carbon dioxide during endoscopic retrograde cholangiopancreatography using a double-balloon endoscope with carbon dioxide insufflation under conscious sedation. Dig Endosc. 2014 May;26(3):436-41.

22. Riphaus A, Wehrmann T, Kronshage T, Geist C, Pox CP, Heringlake S, et al. Clinical value of the Integrated Pulmonary Index during sedation for interventional upper GI-endoscopy: A randomized, prospective tri-center study. Dig Liver Dis. 2017 Jan;49(1):45-9. 
Table 1 Sedation Scales used in this study

\begin{tabular}{|c|c|}
\hline $\begin{array}{l}\text { Modified Observer Assessment of } \\
\text { Alertness/sedation Scale } \\
\text { Sedation score }\end{array}$ & Clinical response \\
\hline 1 & No response to painful stimulus \\
\hline 2 & Responds to panful stimulus only \\
\hline 3 & Responds to loud speech \\
\hline 4 & Lethargic response to speech \\
\hline 5 & Awake, responds to speech readily \\
\hline \multicolumn{2}{|l|}{$\begin{array}{l}\text { Modified Ramsay Sedation Scale } \\
\text { sedation score }\end{array}$} \\
\hline 0 & Paralyzed, unable to evaluate \\
\hline 1 & Anxious, agitated, restless \\
\hline 2 & Co-operative, oriented, calm \\
\hline 3 & Lightly sedated, reacts to speech \\
\hline 4 & Moderately sedated, reacts to tactile stimulus to forehead \\
\hline 5 & Deeply sedated, responds to pain \\
\hline 6 & Deeply sedated, no pain response \\
\hline \multicolumn{2}{|l|}{$\begin{array}{l}\text { Richmond Agitation Sedation Scale } \\
\text { Sedation score }\end{array}$} \\
\hline-5 & $\begin{array}{l}\text { Unarousable, no response to voice, physical stimulation or } \\
\text { pain }\end{array}$ \\
\hline-4 & $\begin{array}{l}\text { Deep sedation, responds only to pain (such as bile duct } \\
\text { dilatation) }\end{array}$ \\
\hline-3 & $\begin{array}{l}\text { Moderate sedation, responds to physical stimulation (such as } \\
\text { shaking, manipulation of the gastroscope) }\end{array}$ \\
\hline-2 & $\begin{array}{l}\text { Light sedation, responds to repeated loud voice, eyes open } \\
<10 \text { seconds }\end{array}$ \\
\hline-1 & $\begin{array}{l}\text { drowsy, not fully alert, but has sustained awakening } \\
\text { (eye-opening/eye contact) to voice (>10 seconds) }\end{array}$ \\
\hline 0 & Alert and calm \\
\hline 1 & Restless, anxious but movements not aggressive, vigorous \\
\hline 2 & $\begin{array}{l}\text { Agitated, frequent non-purposeful movement, fights the } \\
\text { procedure }\end{array}$ \\
\hline 3 & very agitated, pulls or removes catheters; aggressive \\
\hline 4 & Combative, violent, immediate danger to staff \\
\hline
\end{tabular}



Table 2. Demographics, drug consumption, endoscopist and patient satisfaction

\begin{tabular}{|c|c|c|c|c|}
\hline & $\begin{array}{l}\text { PCS } \\
n=39\end{array}$ & $\mathrm{PCS}+\mathrm{AAS} \mathrm{n}=9$ & $\begin{array}{l}\text { PCS solution } \\
\text { administered } \\
\text { by } \\
\text { anesthesiolo } \\
\text { gist } \\
\mathrm{n}=18\end{array}$ & $\begin{array}{l}\text { AAS } \\
n=133\end{array}$ \\
\hline $\begin{array}{l}\text { Duration; minutes } \\
\text { (IQR) }\end{array}$ & $23(12)$ & $20(10)$ & $30(27)$ & $24(19)$ \\
\hline age; years(IQR) & $49(20)$ & $56(17)$ & $65(25)$ & $58(27)$ \\
\hline ASA class $(\%)$ & $\begin{array}{l}\text { I: } 2(5.1) \\
\text { II: } 29(74.4) \\
\text { III:5 (12.8) } \\
\text { IV: } 3(7.7)\end{array}$ & $\begin{array}{l}\text { I: } 0(0) \\
\text { II: } 5(55.6) \\
\text { III:4 (44.4) } \\
\text { IV: } 0(0)\end{array}$ & $\begin{array}{l}\text { I: } 0(0) \\
\text { II: } 6(33.3) \\
\text { III: } 9(50.0) \\
\text { IV: } 3(16.7)\end{array}$ & $\begin{array}{l}\text { I: } 8(6.0) \\
\text { II: } 46(34.6) \\
\text { III:50 (37.6) } \\
\text { IV: } 29(21.8)\end{array}$ \\
\hline 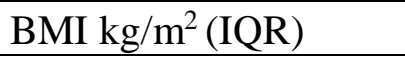 & $25.0(4.0)$ & $24.2(8.5)$ & $22.6(7,2)$ & $25.0(5.0)$ \\
\hline Male/female & $26 / 13$ & 06.02 .16 & $12 / 8$ & $77 / 56$ \\
\hline \multicolumn{5}{|l|}{ drug consumption: } \\
\hline $\begin{array}{l}\text { Dosage of propofol; } \\
\mathrm{mg}(\mathrm{IQR})\end{array}$ & $162(76)$ & $224(112)$ & $212(184)$ & $326(237)$ \\
\hline \multicolumn{5}{|l|}{ alfentanil } \\
\hline $\begin{array}{l}\text { Number of times used } \\
\text { (in addition to PCS } \\
\text { solution) }\end{array}$ & - & - & - & 7 \\
\hline Dosage; mg (IQR) & - & - & - & $0.5(0)$ \\
\hline $\begin{array}{l}\text { total Alfentanil dosage } \\
\mathrm{mg}(\mathrm{IQR})\end{array}$ & $1.2(0.51)$ & $1.5(0.78)$ & $1.59(1.39)$ & $0.5(0)$ \\
\hline \multicolumn{5}{|l|}{ Fentanyl } \\
\hline number of times used & 23 & 5 & 1 & 132 \\
\hline dosage; mg (IQR) & $0.05(0)$ & $0.05(0)$ & $0.05(0)$ & $0.05(0.05)$ \\
\hline \multicolumn{5}{|l|}{ Ketamine } \\
\hline Number of times used & - & - & - & 3 \\
\hline dosage; mg (IQR) & - & - & - & $20(10)$ \\
\hline \multicolumn{5}{|l|}{ Satisfaction } \\
\hline endoscopist & $7(3)$ & $12(2)$ & $7.5(4)$ & $9(2)$ \\
\hline patient & $7(0)$ & $7(1)$ & $7(0.75)$ & $7(1)$ \\
\hline
\end{tabular}

PCS = Patient Controlled Sedation, PCS + AAS = Patient controlled Sedation and Anesthesiologist Administered Sedation, AAS = Anesthesiologist Administered Sedation, IQR = Inter Quartile Range, ASA class = American Society of Anesthesiology physical status classification, BMI = Body Mass Index 
Table 3. Cronbach's alpha, including BiS, mOAAS, mRSS, RASS

\begin{tabular}{|l|l|l|} 
Scores included & $\begin{array}{l}\text { Cronbach's alpha } \\
\text { (lower 95\% CI) }\end{array}$ & Change to all scores included \\
\hline BiS, mOAAS, mRSS, RASS & $0.943(0.938)$ & \\
\hline mOAAS, mRSS, RASS & $0.9745(0.970)$ & 0.03174 \\
\hline BiS, mRSS, RASS & 0.9406 & -0.03645 \\
\hline BiS, mOAAS, RASS & 0.9114 & -0.0314 \\
\hline BiS, mOAAS, mRSS & 0.9018 & -0.04094 \\
\hline
\end{tabular}

$\mathrm{BiS}=$ Bispectral Index, mOAAS=modified Observer Assessment of Alertness and Sedation, mRSS= modified Ramsay Sedation Scale (in reverse order), RASS $=$ Richmond Agitation/Sedation Scale 
Table 4. Prediction probability $\mathrm{P}_{\mathrm{K}}$ and Spearman correlation coefficients

\begin{tabular}{|l|l|l|l|l|l|l|}
\hline & $\mathrm{P}_{\mathrm{K}}$ & $\mathrm{SE}$ & $\mathrm{p}$ & Spearman & $\mathrm{SE}$ & $\mathrm{P}$ \\
\hline mOAAS & 0.739 & 0.01 & $<.01$ & 0.695 & 0.016 & $<.01$ \\
\hline mRSS & 0.735 & 0.01 & $<.01$ & 0.673 & 0.017 & $<.01$ \\
\hline RASS & 0.738 & 0.01 & $<.01$ & 0.683 & 0.017 & $<.01$ \\
\hline
\end{tabular}

mOAAS=modified Observer Assessment of Alertness and Sedation, $\mathrm{mRSS}=$ modified Ramsay Sedation Scale (in reverse order), RASS = Richmond Agitation/Sedation Scale, SE=standard error 
Table 5. Multilevel AUCs for evaluating performance of different scoring systems to predict sedation level.

$$
\begin{array}{ccc}
\text { mRSS } & \text { mOAAS } & \text { RASS } \\
95 \% \mathrm{Cl} & 95 \% \mathrm{Cl} & 95 \% \mathrm{Cl}
\end{array}
$$

\begin{tabular}{lccccccccc} 
Comparison & AUC & lower & upper & AUC & lower & upper & AUC & lower & upper \\
\hline Deep sedation vs light sedation & 0.96 & 0.94 & 0.98 & 0.96 & 0.93 & 0.98 & 0.96 & 0.94 & 0.98 \\
Moderate sedation vs light sedation & 0.80 & 0.76 & 0.84 & 0.80 & 0.75 & 0.84 & 0.81 & 0.77 & 0.85 \\
Deep sedation vs moderate sedation & 0.77 & 0.75 & 0.80 & 0.78 & 0.76 & 0.81 & 0.78 & 0.75 & 0.80 \\
Multilevel AUC & 0.85 & & & 0.85 & & & 0.85 & & \\
\hline
\end{tabular}

mOAAS=modified Observer Assessment of Alertness and Sedation, $\mathrm{mRSS}=$ modified Ramsay

Sedation Scale(in reverse order), RASS= Richmond Agitation/Sedation Scale 
Table 6, Correlation between sedation sacles and endoscopist or patient satisfaction

\begin{tabular}{lcccc} 
& mRSS & mOAAS & RASS & BiS \\
\hline Edoscopist satisfaction & -0.183 & -0.178 & -0.167 & -0.140 \\
Patient satistaction & 0.104 & 0.091 & 0.090 & 0.020 \\
\hline
\end{tabular}

Spearman's rho correlation coefficient, $p \varangle 0.05$, except between BIS and patient satisfaction. mOAAS=modified Observer Assessment of Alertness and Sedation, mRSS= modified Ramsay Sedation Scale (in reverse order), RASS=Richmond Agitation/Sedation Scale, $\mathrm{BiS=Bispectral} \mathrm{Index.} \mathrm{Satisfaction} \mathrm{scales:} \mathrm{endoscopist} \mathrm{lower} \mathrm{is} \mathrm{better,} \mathrm{and} \mathrm{patient} \mathrm{lower} \mathrm{is} \mathrm{worse.}$ 


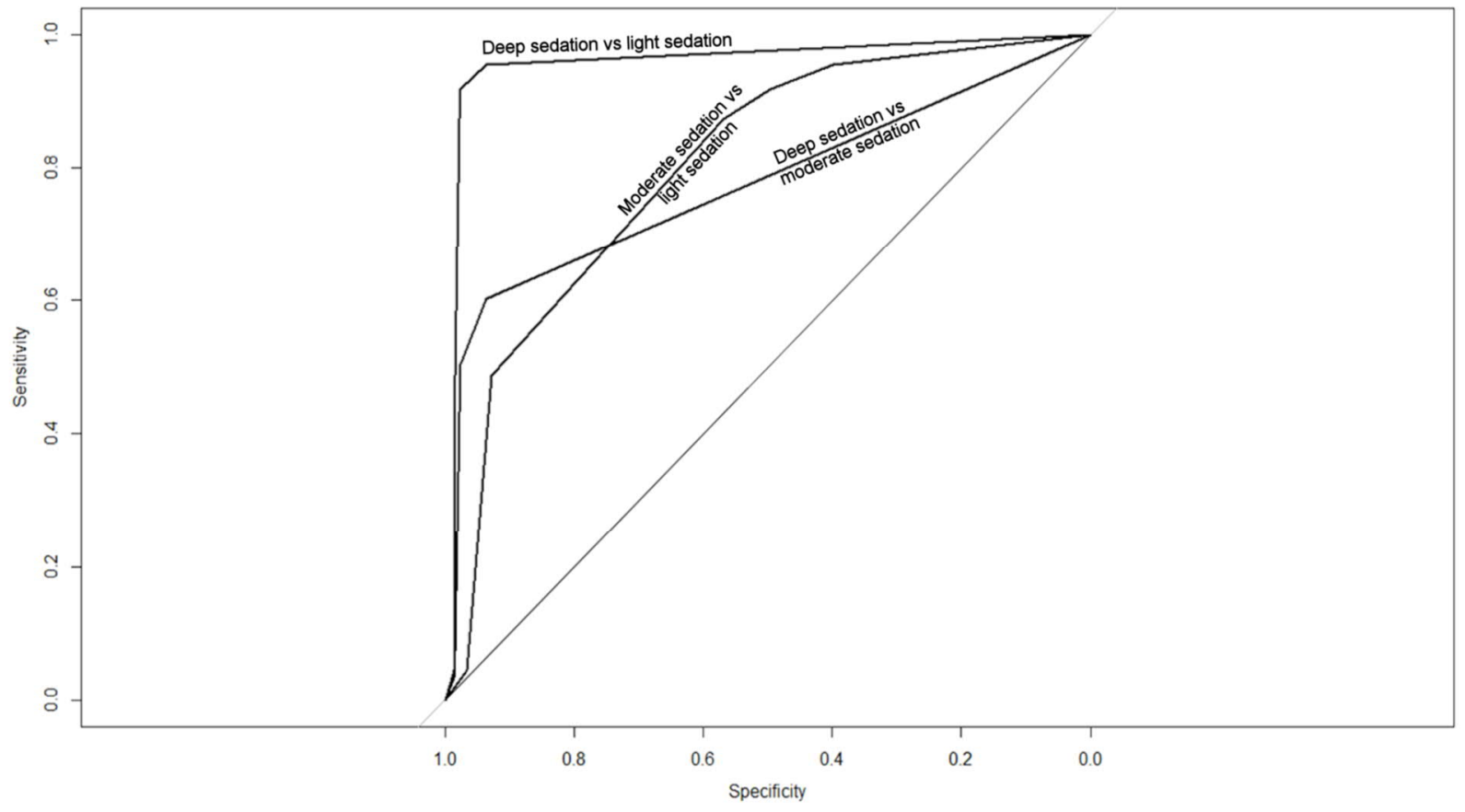

Figure 1 Multilevel ROC for modified Ramsay Sedation Scale.

Multilevel ROC curve for modified Ramsay Scale (mRSS, in reverse order) in relation to Bispectral Index (Bis). BiS was divided into 3 categories: light sedation $\mathrm{BiS}>85$, moderate sedation Bis $65-85$, deep sedation $\mathrm{BiS}<65$, Multilevel AUC for mRSS is 0.845 . 


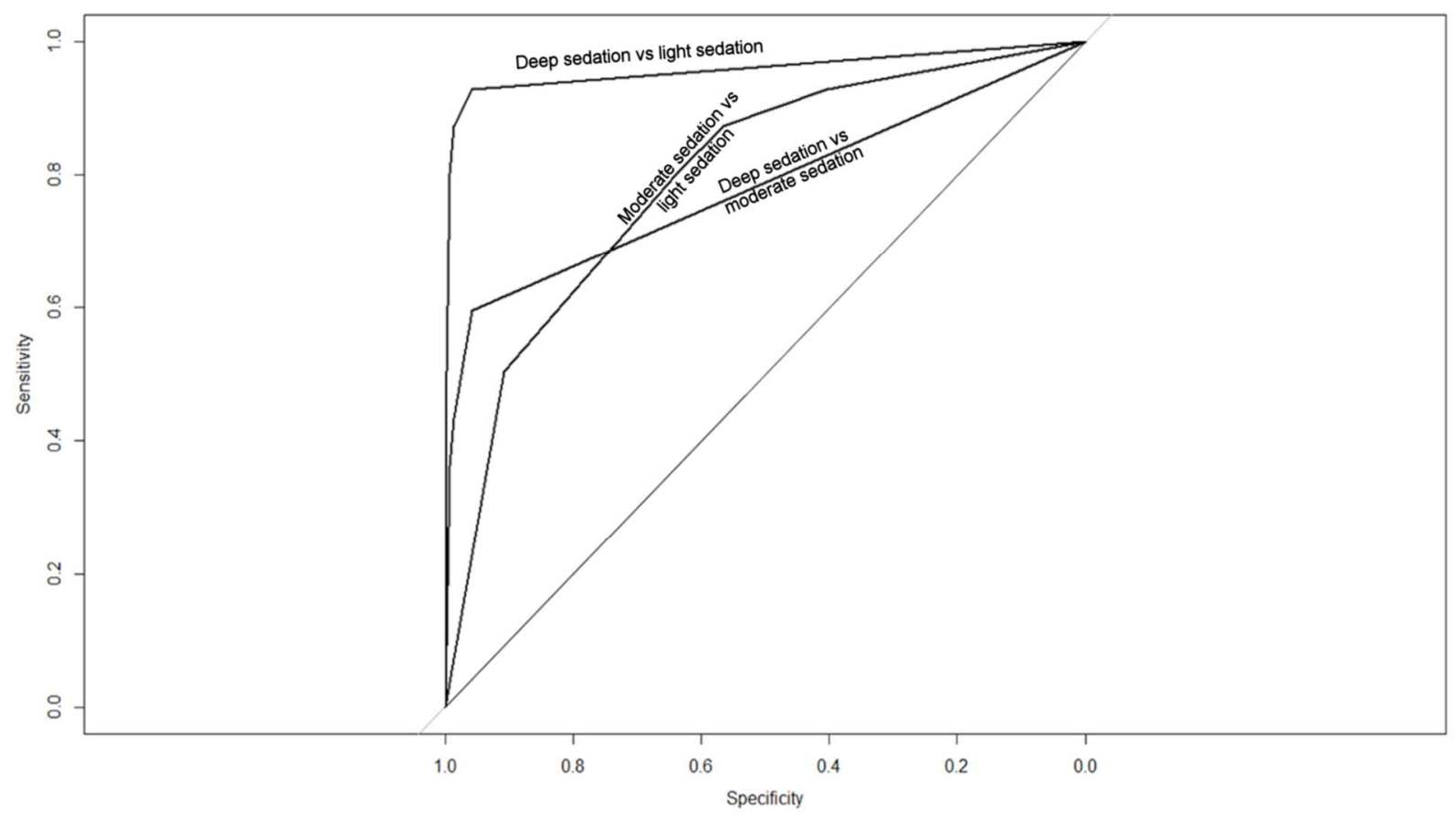

Figure 2 Multilevel ROC modified Observer Assessment of Alertness and Sedation Scale. Multilevel ROC curve for modified Observer Assessment of Alertness and Sedation Scale (mOAAS) in relation to Bispectral Index (Bis). BiS was divided into 3 categories: light sedation BiS $>85$, moderate sedation Bis 65-85, deep sedation BiS $<65$, Multilevel AUC for mOAAS is 0.846 . 


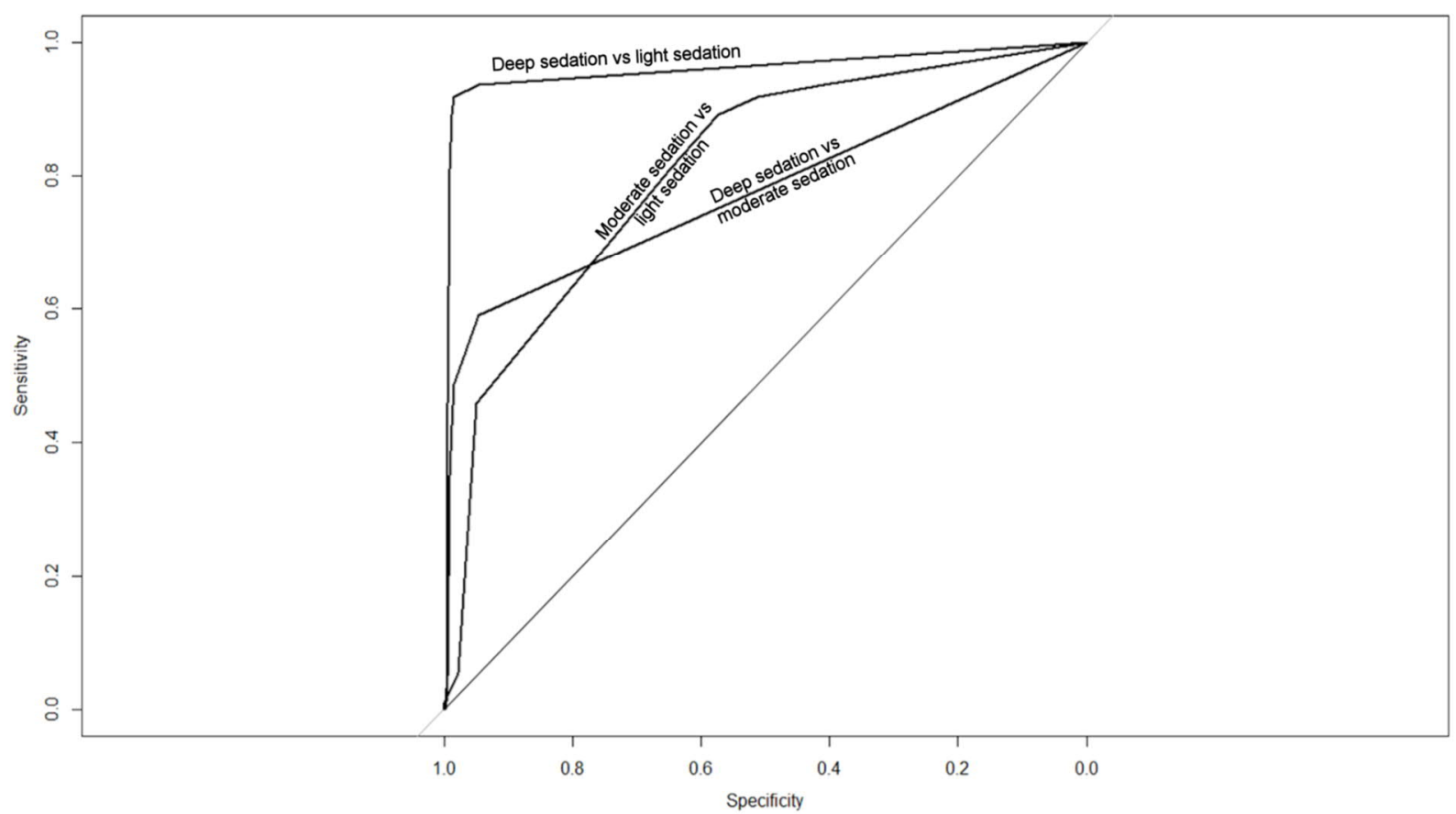

Figure 3. Multilevel ROC for Richmond Agitation/Sedation Scale.

Multilevel ROC curve for Richmond Agitation/Sedation Scale (RASS) in relation to Bispectral Index (Bis). BiS was divided into 3 categories: light sedation BiS $>85$, moderate sedation Bis 65-85, deep sedation BiS $<65$, Multilevel AUC for RASS is 0.849.- 